\title{
Mapping research trends on strategic agility over the past 25 years: insights from a bibliometric approach
}

\author{
Enrique de Diego and Paloma Almodóvar \\ Complutense University of Madrid, Madrid, Spain
}

\begin{abstract}
Purpose - Strategic agility is a fuzzy concept that has become crucial to cope with environmental uncertainty and instability; hence, more in-depth studies are highly needed. The aim of this paper is to shed light on the still diffuse research area of strategic agility by clarifying its scope and concept, as well as identifying the different topics that have been examined thus far. Finally, the intent of this paper is to show the existing gaps in the literature to provide scholars with a clear roadmap for future research.

Design/methodology/approach - Bibliometric and content analyses are used in this study to review the most impactful papers in strategic agility between 1996 and 2021. Citation and mapping analyses are conducted through SciMAT software, and a dynamic approach is adopted by assessing and discussing the evolution of strategic agility throughout five different periods.

Findings - This study reveals that strategic agility is a research line that has neither gained consensus nor reached maturity and that it is linked to several thematic areas or topics. The study offers a complete understanding of the state of the art of strategic agility over time and underscores its main future research lines. Originality/value - This study presents a complete map of the strategic agility research thus far by using novel bibliometric techniques. This approach is especially interesting because it allows for identifying the dynamic relationships among themes within the topic over five different periods.
\end{abstract}

Keywords Strategic agility, Bibliometric analysis, Science mapping, Co-word analysis

Paper type Research paper

\section{Introduction}

Strategic agility has grown as a topic of interest in recent years, with many authors investigating the subject; in particular, strategic agility has gained considerable attention in the current turbulent period caused by the global COVID-19 pandemic (Al-Omoush et al., 2020; Hartwell and Devinney, 2021; Zahra, 2021; Shaikh, 2021), which has accelerated changes already underway in consumer behaviour and in new communication platforms (Hsu and Tang, 2020).

According to Weber and Tarba (2014), the concept of strategic agility was introduced about two decades ago, but it remains ill-defined. Since the work of Abshire (1996), the concept of strategic agility has been used across a series of industries, and authors have

\section{JEL Classification — L20, L22, L29}

(C) Enrique de Diego and Paloma Almodóvar. Published in European Journal of Management and Business Economics. Published by Emerald Publishing Limited. This article is published under the Creative Commons Attribution (CC BY 4.0) licence. Anyone may reproduce, distribute, translate and create derivative works of this article (for both commercial and non-commercial purposes), subject to full attribution to the original publication and authors. The full terms of this licence may be seen at http:// creativecommons.org/licences/by/4.0/legalcode

"Authors would like to thank Professor Julian Birkinshaw for his comments to previous versions of this manuscript".

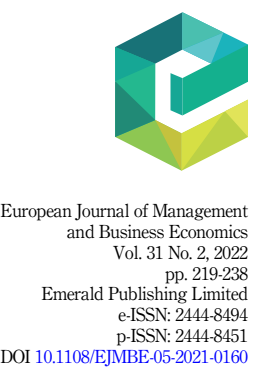


EJMBE 31,2 related this research line with several topics and organisational areas. Furthermore, the authors use the concept with and without proposing a definition.

Starting with agility as a wider topic, consensus on it seems to exist, that is, agility entails rapid responses to changes in the market. For example, Weill et al. (2002, p. 64) define agility as "the set of business initiatives an enterprise can readily implement"; Sambamurthy et al. (2003, p. 238) describe agility as "the ability to detect and seize market opportunities with speed and surprise"; Cohen et al. (2004) argue that being agile means delivering quickly and changing quickly and often; Da Silva et al. (2011) mention that agile methods help deal with growing complexity while reducing time to market; and Aronsson et al. (2011) assert that the focus of agility is being able to compete in a state of constant change and that agile organisations are those that swiftly respond to changes in demand.

The first mention of strategic agility appeared in the late 1990s, when Abshire discussed "a strategy of agility" around the US policy and how to maintain the country's leadership in the world. This author explained that the strategic landscape after the Cold War was characterised by an information age that was unpredictable and unstable. Thus, the US needed to use a strategy that was agile enough to seize opportunities and protect against threats (Abshire, 1996). Several authors have since continued contributing to the interrelationship of both terms.

We find authors who use the terminology "business agility" in relation to strategy and the competitive advantage of a firm. For example, Mathiassen and Pries-Heje (2006) assert that agility is fundamental when planning business strategy and, to be properly implemented, agility must be aligned with the information technology (IT) strategy. These authors highlight the idea that the main path to maintain the competitive strategy is designing an agile business. In this line, Van Oosterhout et al. (2006) focus their research on explaining how the business environment is highly dynamic and that businesses need to be not only flexible but also agile. Thus, business agility is defined as the capability of a firm to rapidly transform business models and processes beyond regular "flexibility" to respond to unpredictable external threats with successful internal changes. More recently, Hendriyani and Raharja (2019) even use the expression "business agility strategy" to define the capacity of a Fintech start-up to detect opportunities and threats and develop an appropriate response.

When explicitly discussing strategic agility, some authors use the term without providing a specific definition. For example, Weill et al. (2002) discuss how the IT infrastructure should be responsive to the demands of enterprise-wide and business unit strategies to ensure strategic agility. Doz and Kosonen (2010) similarly relate strategic agility to the ability to transform and renew business models.

On the contrary, some scholars have clearly defined the topic. For instance, Ekman and Angwin (2007, p. 361) refer to strategic agility as an acknowledgement of "the ever-increasing complexity and turbulence of their environments by developing requisite capabilities of flexibility and responsiveness"; Lewis et al. (2014, p. 58) describe it as "flexible, mindful responses to constantly changing environments"; Weber and Tarba (2014, p. 5) pertain to strategic agility as the "ability to remain flexible in facing new developments, to continuously adjust the company's strategic direction, and to develop innovative ways to create value"; Denning (2018, p. 119) argues that "strategic agility is generating innovations that create entirely new markets by turning non-customers into customers"; and Clauss et al. (2020, p. 3) refer to strategic agility as "a firm's ability to renew itself continuously and to maintain flexibility without compromising efficiency".

In addition to having several definitions, the concept of strategic agility is often related to other topics. In this sense, Sambamurthy et al. (2003) relate agility with ambidexterity, and Ananthram and Nankervis (2013) argue that strategic agility is synonymous with other topics such as dynamic capabilities. Ambidexterity pertains to the organisation's ability to exploit its current capabilities while simultaneously exploring new competencies 
(Raisch et al.,2009; O'Reilly and Tushman, 2013; Pasamar, 2019; Vargas et al., 2021). Although we can perceive a connection between strategic agility and ambidexterity, they are separate concepts (Clauss et al., 2020) that are intertwined at different levels of analysis. Regarding dynamic capabilities, they are defined as the firm's ability to integrate, build and reconfigure internal competencies to address changes in the business environment (Teece, 2017; Schilke, 2018). Accordingly, strategic agility is considered a meta-capability that combines several dynamic capabilities (Ahammad et al., 2021; Shams et al., 2021; Nyamrunda and Freeman, 2021). In this sense, Doz and Kosonen (2010) and Clauss et al. (2021) propose that strategic agility is formed as a combination of strategic sensitivity, leadership unity and resource fluidity; and very closely related Hock et al. (2016) and Ivory and Brooks (2018) also include strategic sensitivity, resource fluidity but considers collective commitment as the third dynamic capability that forms part of strategic agility.

A common pattern seems to emerge, which is related to how organisations can adjust their direction and confront environmental changes. However, a common definition for this concept is lacking, even though it is simultaneously the most demanding item on the leadership agenda for CEOs (Doz and Kosonen, 2008), which makes a compelling case to enhance the understanding of what strategic agility implies both for academics and practitioners. To do so, we first use citation analysis to show that the topic of strategic agility has still not reached the stage of maturity. We subsequently use science mapping analysis to study how the topic has evolved over time and uncover that, while it has attracted significant attention across different sectors, it has still not been fully clarified. Science mapping analysis is a powerful technique that has been previously used (Kamdem et al., 2019; Garcia Buendia et al., 2020), and this method has several advantages over other literature review tools. It allows for handling hundreds of papers to analyse the relationships among elements of the papers (e.g. citations, keywords) and provides comprehensive information about the research area. Finally, we examine all the selected papers to enrich the bibliometric results through the content analysis method that deepens the discussion with the contributions obtained by the academia thus far.

Therefore, the purpose of this study is to analyse the evolution of strategic agility over the 1996-2021 period, attempting to identify a comprehensive definition and the key themes in this field, which have drawn the attention of the research community, and the gaps in the literature. The objective of our paper is threefold. First, we aim to understand the level of maturity of the topic of study. In other words, we intend to ascertain whether this topic is a growing one in the literature or whether it has started to plateau. We also seek to verify the degree of homogeneity of the distributions of authors and journals to explore for other authors the feasibility of publishing on this topic.

Second, we aim to confirm the presence of any key theme to which strategic agility is specifically related and to identify the main gaps in the literature.

Third, we intend to determine the definition that could summarise the meaning of strategic agility.

These three objectives are expected to clarify the topic of study and help in advancing other studies that require a more solid definition of the topic under investigation and its relationship with other subjects.

This paper is organised into several sections. Section 2 introduces the methodology. Section 3 describes and discusses the results of the science mapping analysis. Finally, Section 4 presents the conclusions, limitations and potential areas for further research.

\section{Methodology}

Systematic review papers come in several forms such as structured reviews, bibliometric reviews and hybrid narratives (Dabic et al., 2020). We use a hybrid-narrative approach through which we examine the conceptual structure and set an agenda for future research.

\section{Strategic agility: a bibliometric approach}


EJMBE 31,2

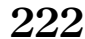

Specifically, we use (1) citation analysis to study the maturity of the topic of strategic agility through time and identify the top journals and the most productive authors in this field and (2) science mapping to assess the conceptual structure of the topic of strategic agility over time. Science mapping is a powerful technique that makes a spatial representation of how different fields or specialities are related to each other (Morris and Van der Veer Martens, 2008; Cobo et al., 2011b). We also conduct (3) content analysis, a qualitative method that complements bibliometric techniques by interpreting and discussing the contribution of papers (Rodriguez Ruiz et al., 2019; Furrer et al., 2008).

Five steps comprise the methodology (Cobo et al., 2011a), namely (1) collection of raw data; (2) selection of the type of item to analyse; (3) extraction of relevant information from the raw data; (4) calculation of similarities among items; and (5) use of a clustering algorithm.

(1) Collection of raw data

This phase is homogeneous for both the citation and science mapping analyses. Bibliometric analyses typically use Thomson Reuters' Web of Science (WoS) and Elsevier's Scopus (Rodriguez Ruiz et al., 2019). To select the most suitable database for our research, we replicated this first phase in both. To download data from WoS and Scopus, we build a query, including descriptive keywords in the topic to collect the relevant documents from the research field (Cobo et al., 2011a). We search for relevant words (e.g. strategic agility, agile strategies, strategic business agility) in the title, abstract or keywords, limiting the type of document to only the ones that are classified as an "article" or a "review". This step ensures that we only consider those publications that have undergone a peer review analysis, guaranteeing a high level of quality of the publications selected (Ramos Rodriguez and Ruiz Navarro, 2004; Fernandez Alles and Ramos Rodriguez, 2009).

On November 19, 2020, the query is run, retrieving 181 results in WoS vs 307 results in Scopus (dated from 1996 to 2021). This result is consistent with the finding of other authors where WoS is less comprehensive than Scopus (Chadegani et al., 2013) and that almost all journals indexed in WoS are also covered by Scopus (Singh et al., 2021). Therefore, after analysing the characteristics of each source and the results provided, we selected Scopus as our dataset because of its broader coverage of journals and citations (Chadegani et al., 2013; Mongeon and Paul-Hus, 2016; Harzing and Alakangas, 2016; Zhu and Liu, 2020). Therefore, we choose to work with the dataset of 307 articles provided by Scopus, in place of the 181 provided by WoS. Notably, even when we could manually identify the few papers from WoS that are not included in Scopus with the intention of integrating the results from both article sources, we do not merge the results from Scopus and WoS because the criterion we use to evaluate documents is the number of citations, and this criterion is not homogeneous among sources. WoS and Scopus codify "citations" following different approaches (Martin-Martin et al., 2018); hence, we only use the results from Scopus to obtain unbiased results.

By running the query in Scopus, we also perform a citation analysis, as Elsevier's website provides a 15-year evolution of the citations in the selected documents. As Figure 1 shows, a growing trend in the topic is apparent, and authors link an increase of citations to the evolution of an emerging phase to a mature one (Terjesen et al., 2016; Rodriguez Ruiz et al., 2019). Strategic agility has not yet reached a maturity level.

We use SciMAT to perform our bibliometric analyses because it has a wider range of features than other software tools (e.g. BibExcel), and it enables a longitudinal framework across different time periods (Cobo et al., 2012). Moreover, the tool enriches the results by using impact measures (e.g. h-index, sum of citations) that help improve the interpretation of the results. It also presents key features unseen in other mapping tools, such as a preprocessing module, the use of bibliometric measures and a wizard to configure the analysis (Cobo et al., 2012). 
After reviewing the 307 documents downloaded from Scopus, we eliminate the ones that are far from the concept of the study, eventually obtaining a final dataset of 293 documents (Rodriguez Ruiz et al., 2019; Xue et al., 2020).

The most productive journals and authors in the dataset are outlined in Table 1 . We observe that the distribution in the journals and authors is quite homogeneous, suggesting that it is a concept covered by several disciplines and that new authors might find that publishing on this research line could be a feasible option.

Strategic

agility: a

bibliometric

approach

223

\begin{tabular}{lr}
\hline Journal & Documents \\
\hline
\end{tabular}

California Management Review

Strategic Direction

Cutter IT Journal

European Journal of Information Systems

MIS Quarterly Executive

Human Resource Management Review

International Journal of Supply Chain Management

International Journal of Production Economics

Journal of Information Technology

Management Decision

IEEE Software

Global Journal of Flexible Systems Management

Journal of International Management

International Marketing Review

8

6

6

5

5

5

5

4

4

4

4

4

4

4

Author

Luftman, J

Ambler, S.W

Liu, Y

Zadeh, H.S

Gomes, E

Muthuveloo, R

DozY, L

Kosonen, M

Ben-zvi, T

Tarba, S.Y

Derksen, B

Santana, M

Vrontis, D

Denning, S
Table 1.

Journals and authors with the most publications

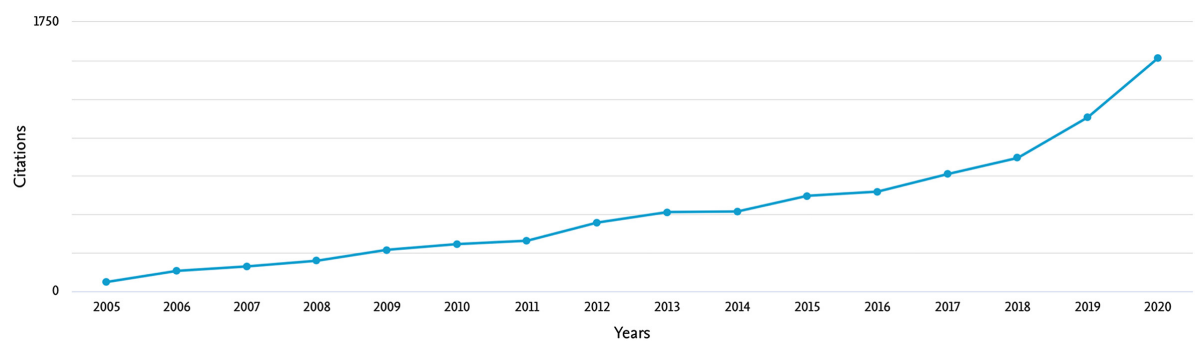

Figure 1. Evolution of the citations per year 
EJMBE 31,2

\section{4}

(2) Selection of the type of item to analyse

We continue the science mapping analysis and choose "keywords" as our object of analysis. "Keywords" is one of the most commonly selected metrics to evaluate (Börner et al., 2003), and we use keywords to analyse and track the evolution of the main topics in the literature.

(3) Extraction of relevant information from the raw data

As we download and import the data into SciMAT, we run a deduplicating process over the keywords to group those terms with the same concept (i.e. grouping plural and singular words, integrating acronyms with the respective keywords, adding together different spellings of the same words). Finally, some keywords with a very broad and general meaning, such as "agility", are removed (Cobo et al., 2014).

To develop the study, the entire time period (1996-2021) is divided into five consecutive periods of time (Figure 2), namely, 1995-2005 with 25 documents, 2006-2009 with 43, 2010-2013 with 38, 2014-2017 with 84 and 2018-2021 with 103 documents. Providing periods of the same length is a common practice, while fixing the first period to cover a larger number of years as the study field begins to consolidate as a discipline (Cobo et al., 2011a).

(4) Calculation of similarities among items

To normalise the co-occurrence of keywords, we use the equivalence index, which is regarded as the most appropriate measure for normalising co-occurrence frequencies (Callon et al., 1991). This index ranges from 0 to 1, where 1 means that the keywords always appear together and 0 denotes that the keywords are never associated (Cobo et al., 2011a).

(5) Use of a clustering algorithm

Clustering is the process of identifying those subgroups of keywords that are strongly linked with each other. Clustering has different types, including spectral clustering and modularity maximisation (Chen and Redner, 2010; Chen et al., 2010), but we use the simple centre's algorithm because it is straightforward and extensively used in the context of co-word analysis (Bailon-Moreno et al., 2005, 2006; Coulter et al., 1998; Courtial, 1990; Courtial and Michelet, 1994; Lopez-Herrera et al, 2009, 2010; He, 1999).

Figure 2.

Number of publications per year of papers focussed on "strategic agility"

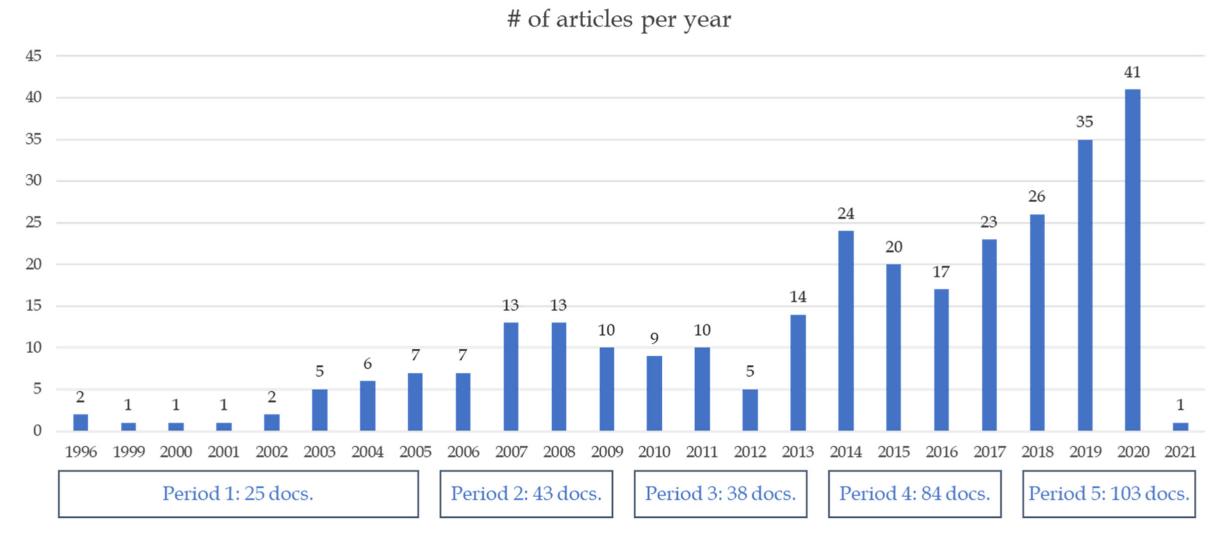




\section{Science mapping analysis of the topic of strategic agility}

\subsection{Results and discussion}

After running the analysis with SciMAT following the approach described above, we obtain two different viewpoints (longitudinal and period views). In the longitudinal representation (Figure 3), we observe a thematic evolution of the research field across the five periods.

We observe that for the first two periods (1996-2005 and 2006-2009), the academia was focussed on discussing strategic agility in relation to two main (and related) topics: "information technology" (IT) and "information systems". However, from 2010 onwards, various research topics began to emerge, with the most recent years (2018-2021) seeing the greatest proliferation of research topics.

Regarding the period representation, we complement the previous longitudinal approach with a strategic diagram that presents a two-by-two matrix. This figure represents on its abscissa axis, the centrality (that measures the degree of interaction of a network with other networks), and on its ordinate axis, the density (measures the internal strength of the network) (Callon et al., 1991; Cobo et al., 2011a, b, 2012). Therefore, the strategic diagram comprises four quadrants illustrating four types of topics according to the quadrant in which they are positioned (Cahlik, 2000; Callon et al.,1991; Courtial and Michelet, 1994; Coulter et al., 1998; He, 1999). The (1) topics in the upper right are the ones known as "motor" themes, being externally related to concepts applicable to other themes that are conceptually closely related; (2) topics in the upper left are isolated themes that are only of marginal importance for the field; (3) topics in the bottom right are important themes for a research field but not developed; and (4) topics in the bottom left are emerging or declining themes.

SciMAT incorporates features that allow for conducting performance analysis, such as the number of citations or h-index (Cobo et al., 2012). It facilitates the identification of the degree of importance of each theme according to the selected metric. In this case, strategic diagrams show themes in different sizes according to their h-index (i.e. the larger the size of the bubble, the higher is the h-index).

Figure 4 depicts the results of the analysis and shows that in the study of strategic agility, "information technology" and "information systems" are key topics during the periods 19962005 and 2006-2009, respectively. Although these topics are sometimes used interchangeably (Checkland and Holwell, 1997), they are not the same. According to Lee (1997) and Onn and Sorooshian (2013), "information technology" is a narrower topic, which refers to the technologies and infrastructures used for processing, storing and transmitting the information. By contrast, "information system" is a broader topic that pertains to the management of information, and it includes computer-based and non-technological systems. However, we acknowledge that both topics are referred to in a similar manner with respect to strategic agility because information systems can hardly be properly developed without considering information technology (Zhu, 2009).

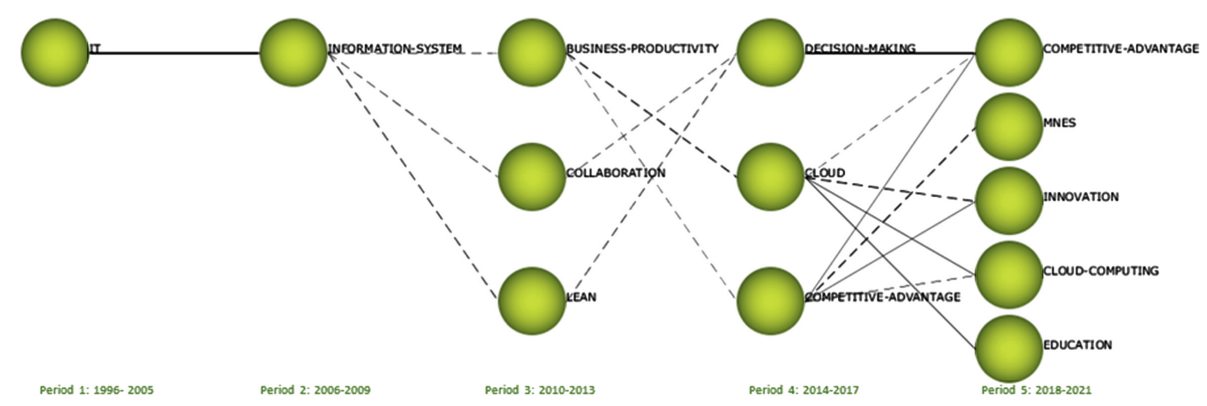

Strategic agility: a bibliometric approach

225
Figure 3. Longitudinal view of the topic across the five study periods 
EJMBE

31,2

226
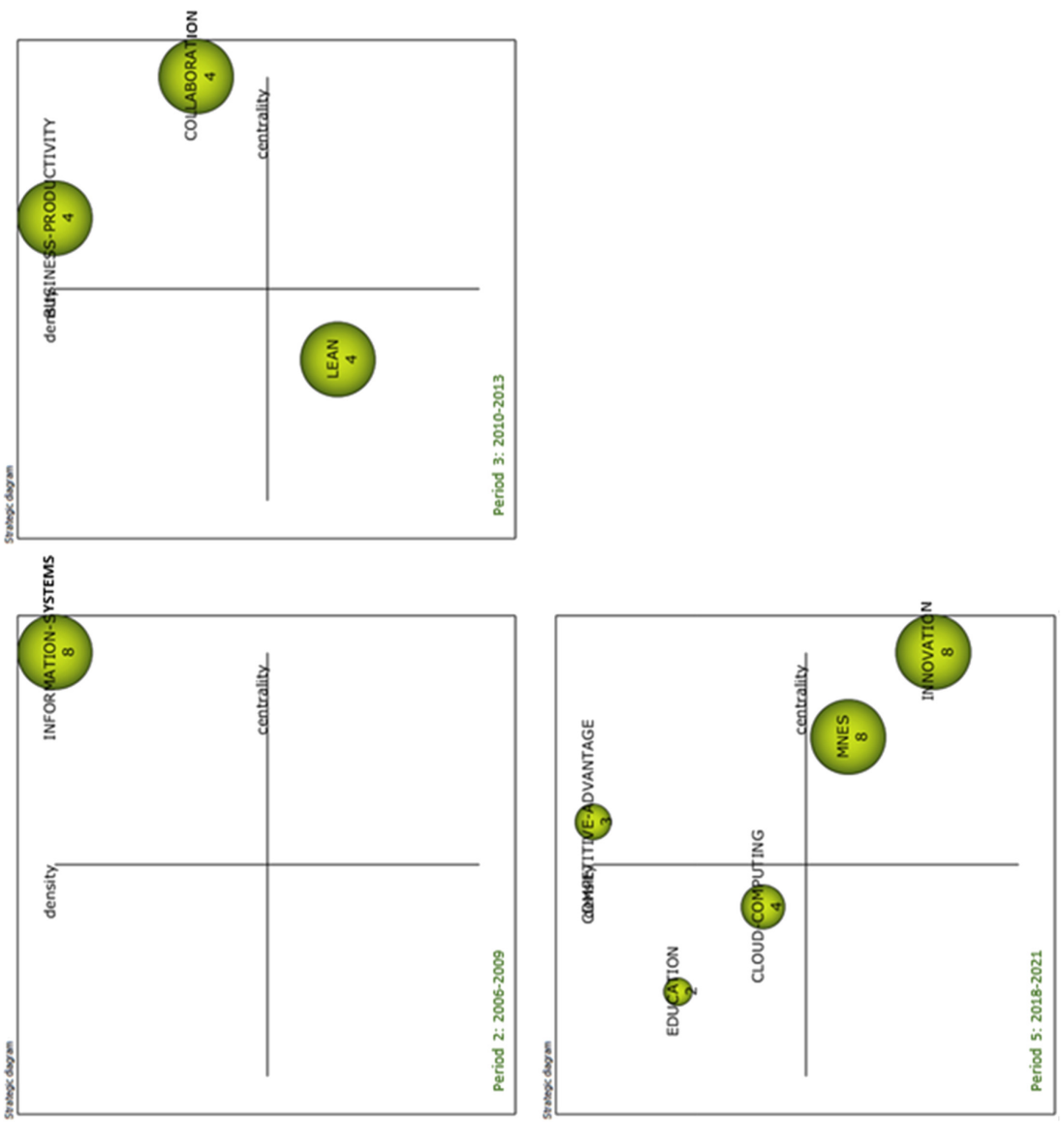

Figure 4.

Strategic diagrams for each study period
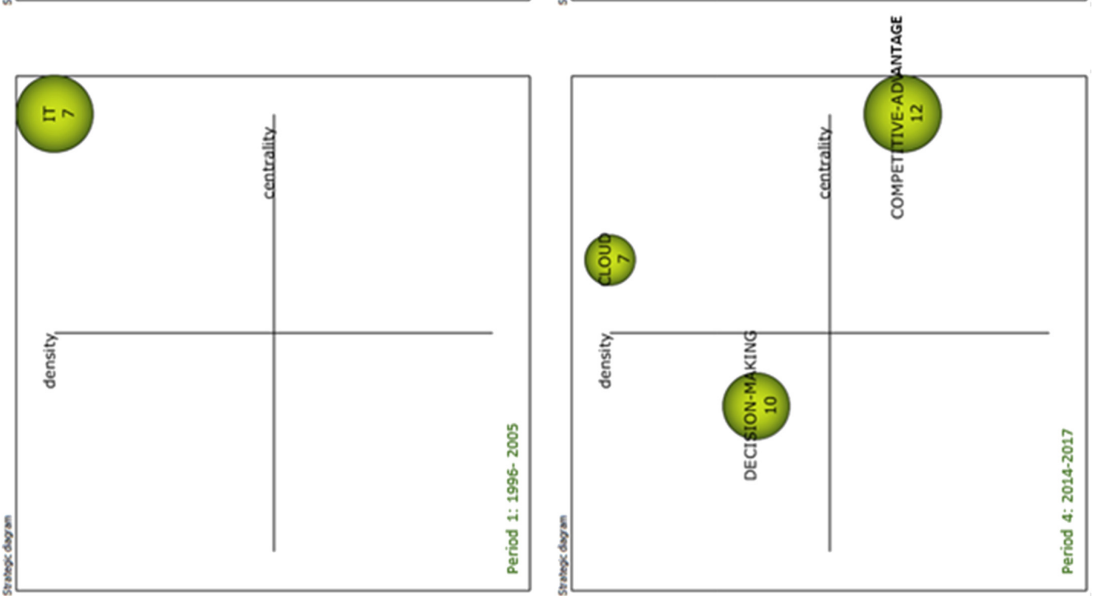
From 1996 to 2005, most authors focus their research on discussing how different aspects of "information technology" (IT) are fundamental to the achievement of a more agile strategy (Worthington, 2004). For example, Weill et al. (2002) state that developing an IT infrastructure is a core requirement for attaining strategic agility. In this sense, these authors unpack the elements needed to develop a robust IT infrastructure (i.e. channel management, security and risk management, communication, data management, application infrastructure, facilities management, IT management, IT architectures and standards, IT education and IT research and development). Sambamurthy et al. (2003) explain that IT includes elements such as data warehousing, web services and customer relationship or supply chain management technologies; they also propose that investing in IT enhances the strategic agility of a firm, and this undertaking has a positive impact on its financial performance. Ross and Westerman (2004) go one step further by suggesting that outsourcing IT will facilitate strategic agility because accessing specialised IT services when needed enables firms to reduce costs and to fully exploit environmental opportunities.

From 2006 to 2009, the main focus shifted towards the broader concept of "information systems", although references to IT are not abandoned. For example, Fink and Neumann (2007) posit that "information technology" reinforces strategic agility only when "information systems" implement agile procedures. Meanwhile, Ekman and Angwin (2007) jointly study "information systems" and "information technology" and how they are the antecedents of strategic agility in the sense of leveraging resources, mastering change, enriching customers and cooperating to compete.

In the third period, covering 2010-2013, different topics start to emerge, and we observe how "business productivity" and "collaboration" position as the motor themes. In this sense, Kristianto et al. (2010) support that agile strategic inventory allocation reduces the inventory level and increases production output and variety. Bottani (2010) examines the profiles of agile companies, collaboration being one the metrics or the one from Aronsson et al. (2011) who study the relevance of combining lean and agile process strategies to develop the supply chain in the health-care sector. "Lean" is, therefore, an emerging theme in this period, and it is jointly analysed with strategic agility as a response to dynamic and non-stop changes that maintain the competitiveness of firms. Thus, some authors use the term leagility as the combination of "lean" and "agility" (Aronsson et al., 2011; Vinodh and Aravindraj, 2013) because agility is a determining factor for a correct supply chain strategy (Fernando and Wulansari, 2020), and supply chain strategies are critical for the competitiveness of firms (de Jesus Marques and Guerra, 2019). Nonetheless, agility is different from leanness. As previously mentioned, agility refers to a rapid response to and the exploitation of profitable opportunities in the dynamic environment; on the contrary, leanness is mainly focussed on reducing the number of suppliers, creating beneficial supplier collaborations, identifying the best just-in-time principles, fostering productivity and reducing time (Naim and Gosling, 2011; Naylor et al., 1999; Aronsson et al., 2011). Thus, lean production implies moving away from vertical integration and relying on cooperation (Badillo et al., 2017).

In the fourth study period of 2014-2017, we observe how the topic of "information technologies" is once again present in the analysed articles; however, during this period, the particular focus is on the "cloud". "Cloud" is the motor theme, with several articles tackling the relationship of the cloud and the achievement of agility. Wang and He (2014) explain how the "cloud" (referring to IT concepts such as SaaS, PaaS and IaaS) is one of the major "information technologies" for achieving strategic agility, and these authors support their proposal in the context of Taiwan. "Competitive advantage" appears as an important topic that is yet to be fully developed, emerging in only a limited number of studies. For example, Kappelman et al. (2014) underscore that cloud computing is one of the largest and most important IT investments undertaken by organisations, and that the "cloud" is used for reinforcing the "competitive advantage" of a firm and developing strategic agility. Finally, 
EJMBE 31,2

\section{8}

"decision making" appears as a topic of marginal importance. In this vein, Lewis et al. (2014) indicate that leadership is a fundamental attribute of handling tensions in situations in which managers apply a decision-making process characterised by a strategic agility approach. Haider and Mariotti (2016) investigate the managers' process of "decision making" in which strategic agility is considered an essential managerial competency that enables firms to constantly adapt and remain competitive.

In the fifth and final period covering 2018-2021, "competitive advantage" matures to become the motor theme. Nejatian et al. (2019) define strategic agility as a metacapability comprising three dynamic capabilities, namely, strategic sensitivity, leadership unity/collective commitment and resource fluidity (previously identified by Doz and Kosonen (2010) and Doz and Kosonen (2008)), and this meta-capability is crucial to achieving "competitive advantage". Similarly, with a sample of 150 German mid-sized firms, Clauss et al. (2020) analyse the relationship between ambidexterity (exploitation and exploration approaches) and strategic agility with "competitive advantage". They explain that ambidexterity is intended to neither enhance the "competitive advantage" of firms nor gain superior benefits, so they obtain a negative effect. However, the interaction between strategic agility and the firm's exploitation positively affects the "competitive advantage" of firms, as these firms report more innovations and higher financial returns.

In the lower right quadrant of this last period, we find "MNEs" and "innovation" as themes of relevant importance, which have yet to be fully developed, and only a small number of articles tackle these topics. Regarding "MNEs", Luo et al. (2020) find evidence about the role of strategic agility, foreign subsidiary autonomy and global integration capability in Chinese "MNEs" in the sense of potential boosters of the geographic dispersion on productivity. With regard to "innovation", Kohtamäki et al. (2020) define three practices and nine micro practices to shape what they consider strategic agility in "innovation". They propose that following these practices, firms will obtain positive profits from entrepreneurial orientation and absorptive capacity. Furthermore, considerable attention is paid to business model "innovation" and the lean and agile principles that must be adopted to foster its accomplishment. Ghezzi and Cavallo (2020) conclude that a lean start-up approach facilitates business model "innovation" (within the perspective of strategic agility) in digital environments.

Finally, "education" and "cloud computing" materialise as isolated themes. Although some articles are still related to cloud computing, they seem to be less predominant than in other periods. On the contrary, the topic of "education" makes its appearance, with authors studying agile strategies for teams in online higher education (Noguera et al., 2018). As a summary, we observe a high number of very different topics related to the research line of strategic agility.

As a complementary analysis, SciMAT plots cluster networks for each theme. We found results similar to the previous ones [1].

\subsection{Holistic considerations about the science mapping results}

3.2.1 IT as a recurring theme. Overall, we note a recurring theme of the topic of strategic agility and IT. This observation is consistent with the fact that the first mentions of strategic agility occur with IT-related topics (Weill et al., 2002; Sambamurthy et al., 2003). IT remains a concept of study across the five periods, in which it is treated as a more generic topic in the first years, and it specialises towards cloud-related topics in the later years. In the first period (1996-2005), Weill et al. (2002) posit that strategic agility requires investing in IT infrastructure; Sambamurthy et al. (2003) argue that IT and IT capabilities enable firms to develop agility; and Ross and Westerman (2004) link strategic agility with utility computing 
(which in turn they define as a collection of technologies and business practices that enables computing to be delivered seamlessly and reliably across multiple computers).

The second period (2006-2009) includes further studies on the effect of IT capabilities on strategic agility, such as Fink and Neumann (2007) who argue that infrastructure capabilities and strategic agility are directly correlated, and Ekman and Angwin (2007, p. 361) who examine the issue of whether information services/IT "is not only part of the industry-level problem of ever-increasing complexity and turbulence, but also is a part of an organisationallevel solution as an enabler of strategic agility".

The third period (2010-2013) continues to be characterised by studies relating to strategic agility and IT, such as Mavengere (2013) who asserts that several IT services are required to promote such strategic agility. The other studies that emerge link strategic agility with IT and organisation, such as Bottani (2010) who indicates that two attributes (employees' role and competency and technology) are the most relevant in agile companies, and Ananthram and Nankervis (2013) who investigate the links between human resource management (HRM) and strategic agility. In this third period, some articles start exploring the relationships with the cloud (e.g. Nguyen et al. (2012); Luftman et al. (2013)).

In the fourth period (2014-2017), additional studies on strategic agility and IT arise, particularly focussing on the cloud and other additional topics. These topics include (1) smalland medium-sized enterprises, where Wang and He (2014) examine the strategies of small cloud service providers in Taiwan as they are associated with firm agility; (2) institutions, where Turner (2014) argues that the cloud has transformed the way that organisations consume IT services as they promise greater agility; and (3) leadership, where Lewis et al. (2014) conclude that leadership is central to managing the tensions of strategic agility and illustrate their point with several examples, one of which (IBM) is in the IT consulting sector.

Finally, in the fifth period (2018-2021), IT remains a concept of the study, but it is decoupled in two areas. First, the authors write about strategic agility and IT in relation to competitive advantages, such as Suradi et al. (2020) who study the mediating effect of strategic agility in supply chain activities and firm performance, and Hamsal et al. (2020) who examine the impact of IT and supply chain management on competitive advantage in the Indonesian retail industry. Second, the authors in the fifth period write about how cloud computing plays a particular role in Industry 4.0, such as Sharma and Sehrawat (2020) who explore cloud computing adoption in the manufacturing sector in India and reveal that this sector is in the transformation phase of Industry 4.0.

Altogether, we observe that information technologies are fundamental to the development of responsive strategies (Kazakov et al., 2020). Hence, they constitute a key element in the implementation of strategic agility.

3.2.2 Interrelationship of strategic agility with other topics. In addition to the recurring theme of IT across the five periods (including cloud in the later ones), we observe other topics to which strategy agility is related.

Mentions of leadership and organisation are made, where Lewis et al. (2014, p. 58) argue that "Leadership is central to managing tensions of strategic agility" and explain that "Leadership entails the ability to identify and leverage opportunities and threats, and to exploit internal and external competencies". Furthermore, Doz and Brannen (2012) investigate the importance of language in the organisation and conclude that language conditions the strategic agility of organisations.

Mentions of manufacturing and supply chain are similarly made, such as Vazquez-Bustelo et al. (2007) who study the main manufacturing strategies and policies of industrial companies in Spain and suggest that firms must adopt agility enablers or practices during turbulent conditions, Qi et al. (2009) who explain how different researchers have extended the idea of agility to supply chains, and Gligor et al. (2015) who conduct an investigation that establishes a positive relationship between an improved ability to meet customer 
EJMBE 31,2 requirements and an increase of supply chain agility in an organisation. Other authors discuss the topic of strategic agility intertwined with knowledge management, including Malhotra (2005) who highlights the critical importance of integrating knowledge management with business processes to achieve strategic agility; or marketing, where Johnston (2009) extends the marketing myopia concept to promote strategic agility.

3.2.3 Strategic agility across industries. The academia has evaluated strategic agility across different industries. These industries include (1) telecommunications, where Doz and Kosonen (2008) analyse Nokia's evolution over 20 years and propose a framework for enabling organisations to maintain and regain strategic agility as they mature; (2) tourism, where Buhalis and O'connor (2005) argue that agile strategies are required to enhance the innovation and competitiveness of tourism organisations; (3) automotive, where Elmoselhy (2013) explores how agile strategies could be implemented in the automotive sector, simultaneously with lean ones; (4) oil and gas, where Shuen et al. (2014) use the dynamic capabilities framework for enhancing the strategic agility of high-tech firms operating in high-velocity markets such as the upstream oil and gas sector; (5) electronics, where Clauss et al. (2021) study German firms in the electronics industry and conclude that strategic agility is positively related to business model innovation; (6) fashion, where Cerruti et al. (2016) examine agile supply partnerships in Italian fashion companies and empirically evaluate the supply characteristics required to foster an agile strategy; (7) banking, where Ezcan et al. (2020) analyse large construction organisations in Turkey to highlight that IT needs to be adopted/diffused to support agility; and (8) education, where Noguera et al. (2018) review how agile strategies are useful for team regulation and project management.

3.2.4 Comprehensive definition and scope of strategic agility. After reviewing the 293 papers, we define strategic agility as a meta-capability that enables organisations to anticipate, react and seize rapid changes in the environment by redefining their corporate strategies and adapting their competitive and functional strategies to survive and create value.

Strategic agility heavily relies on IT for information surveillance to accurately and rapidly implement new or modified strategies. Depending on the strategic level that is affected, strategic agility can be linked with (1) corporate elements such as collaboration agreements and internationalisation (Ahammad et al., 2021), (2) competitive elements such as innovation and productivity (Dabic et al., 2020), or (3) functional elements such as HRM, marketing and operation systems (Ambituuni et al., 2021; Cheng et al., 2020).

3.2.5 Future lines of research. Through bibliometric and content analyses, we have identified the main topics examined in the strategic agility line of research. We observe that the relationship between strategic agility and IT has gained the considerable attention of the academia; however, the rest of the topics require a higher level of analysis and contrast. In addition, we find that a vast range of topics have not yet been addressed or are just emerging. For example, Santiago (2019) explains that human capital is extremely important for firms in order to enhance their sustainability and growth, and Simoes et al. (2019) highlight the relevance of corporate social responsibility and ethical infrastructure when examining human resources practices. Therefore, a line of research with great potential would be to analyse how to identify the most suitable professional profiles to support the strategic agility of organisations and how to retain such profiles with ethically HRM practices.

Furthermore, literature on international business analyses how different firm-specific advantages impact on firm's internationalisation (Rugman, 1981; Buckley and Casson, 1976), and some recent research analyses the reverse effect of how different outputs of internationalisation has a positive impact on enhancing internationalisation itself. For example, how different international "contacts" impact positively a firm's innovation (Almodóvar et al., 2014, 2021; Salomon and Shaver, 2005; Jin et al., 2019). Therefore, an interesting new approach would be to investigate the effect of strategic agility on the 
internationalisation process of firms, as well as its reverse effect, and to determine whether more internationalised firms require and encourage more agile decision-making.

\section{Conclusions}

A literature review of strategic agility is conducted in this research, in which the authors not only explore the key themes through bibliometric techniques but also perform a revision of the key literature to uncover the relationships between strategic agility and other themes. This research line has become particularly important in recent times, especially since the pandemic caused by COVID-19, which has created strong disruptions in all industries. The agility in response has been decisive for the survival of firms. However, the review of the literature indicates that strategic agility is a concept with ambiguously defined limits and scope and that many gaps exist in the literature.

The concept of agility began to be discussed in a generic and imprecise manner. It was subsequently applied to different areas of the company. Hence, strategic agility should be a perfectly clear concept placed at the corporate level and implemented at the competitive and functional levels. However, these boundaries are not clearly defined thus far.

In this line, we review the authors and journals on the topic of strategic agility. We find that the concept of strategic agility has yet to reach the maturity stage. In addition, we recognise an increasing interest in the academic literature both in the number of papers published and in the number of citations these papers obtain. However, we do not observe an outlier in authors and journals that write on the topic; instead, we find a relatively homogeneous distribution, with a large number of authors publishing in a sizeable quantity of journals. Furthermore, we propose a definition that encompasses the key aspects reviewed in the literature. We consider that strategic agility is a meta-capability that enables organisations to anticipate and/or react to rapid changes in the environment by redefining their corporate strategies and adapting their competitive and functional strategies accordingly, with the purpose of surviving and creating value.

Our study shows that strategic agility is a promising line of research; hence, many aspects merit an in-depth exploration and new ones await development. Through our scientific mapping techniques, we have dynamically analysed the evolution of strategic agility over five time periods. Our longitudinal view allows us to observe IT as a recurring topic from 1996 to the present day. Thus, from the very beginning, special attention has been paid to how IT development and improvements are key elements in making the company agile in the implementation of its strategies. Over time, strategic agility has been analysed with respect to the concepts of lean production and collaborative agreements, as well as how strategic agility is related to business productivity. In the fourth stage, we observe that strategic agility is considered a key element to achieve the competitive advantage of a firm. We also observe how decision-making should be conducted so that the company is capable of reacting in a more agile way to changes in the environment, and special attention is paid to cloud technologies to improve the agility of a strategic firm. Finally, in the fifth and final stages, we uncover that more areas begin to emerge. Competitive advantage is again a relevant topic; research focusses on its relationship with business innovation; and it is once again analysed with respect to cloud computing technologies. Notably, strategic agility is discussed in the international arena by investigating how MNEs strive to become agile. Finally, this area of research is transferred to the specific industry of education.

Our study not only highlights the academics' growing interest in strategic agility and its impact on different key areas of the firm but also identifies areas where the impact of strategic agility has not yet been adequately analysed. Strategic agility might be examined with respect to the firm's corporate level (e.g. its link with corporate social responsibility, how to implement rapid and precise changes on corporate strategies such as mergers and

\section{Strategic agility: a bibliometric approach}


EJMBE 31,2

\section{2}

acquisitions or even how internationalisation might compel firms to become more strategically agile); firm's competitive level (e.g. its impact on radical or incremental innovations, or how to reconfigure the firm's competitive strategy to remain cost or quality leaders); firm's functional level (e.g. how to adapt marketing mix strategies to maintain or enlarge the market share, or how to qualify employees to foster the firm's agility). Further analysis regarding the ways in which companies achieve agile strategic decision-making and, in turn, the evaluation of its impact on different measures of firm performance, are needed.

Our study is not without some limitations. First, our sample compiles 293 papers. Although this quantity is an appropriate number to conduct a bibliographic analysis, sample sizes of 1,000 papers are more commonly used (Rogers et al., 2020); hence, having had a larger sample might have been beneficial. Notably, the small number of papers found in Scopus underlines that this area of research is in a growth phase and that there is still much room for further research.

In addition, the analysis in this study was performed by downloading from Scopus a set of documents that matched specific keywords. Scopus database is the largest searchable citation and source of searching literature (Chadegani et al., 2013), and the overlap with other databases such as WoS is considerable (Jacso, 2005). However, Scopus does not cover the entire universe of publications (Vieira and Gomes, 2009).

\section{Note}

1. Figures for cluster networks and comments are available upon request.

\section{References}

Abshire, D. (1996), "U.S. global policy: toward an agile strategy", Washington Quarterly, Vol. 19, pp. 38-61.

Ahammad, M.F., Basu, S., Munjal, S., Clegg, J. and Shoham, O.B. (2021), "Strategic agility, environmental uncertainties and international performance: the perspective of Indian firms", Journal of World Business, Vol. 56, pp. 1-13.

Al-Omoush, K.S., Simón-Moya, V. and Sendra-García, J. (2020), "The impact of social capital and collaborative knowledge creation on e-business proactiveness and organizational agility in responding to the COVID-19 crisis", Journal of Innovation and Knowledge, Vol. 5, pp. 279-288.

Almodóvar, P., Saiz-Briones, J. and Silverman, B.S. (2014), "Learning through foreign market participation: the relative benefits of exporting, importing, and foreign direct investment", The Journal of Technology Transfer, Vol. 39, pp. 915-944.

Almodóvar, P., Nguyen, Q.T.K. and Verbeke, A. (2021), "An integrative approach to international inbound sources of firm-level innovation”, Journal of World Business, Vol. 53, pp. 1-12.

Ambituuni, A., Azizsafaei, F. and Keegan, A. (2021), "HRM operational models and practices to enable strategic agility in PBOs: managing paradoxical tensions", Journal of Business Research, Vol. 133, pp. 170-182.

Ananthram, S. and Nankervis, A. (2013), "Strategic agility and the role of HR as a strategic business partner: an Indian perspective", Asia Pacific Journal of Human Resources, Vol. 51, pp. 454-470.

Aronsson, H., Abrahamsson, M. and Spens, H. (2011), "Developing lean and agile health care supply chains”, Supply Chain Management: An International Journal, Vol. 16, pp. 176-183.

Badillo, E.R., Galera, F.L. and Serrano, R.M. (2017), "Cooperation in R\&D, firm size and type of partnership: evidence for the Spanish automotive industry", European Journal of Management and Business Economics, Vol. 26, pp. 123-143.

Bailon-Moreno, R., Jurado-Alameda, E., Ruz-Banos, R. and Courtial, J. (2005), "Analysis of the scientific field of physical chemistry of surfactants with the unified scientometric model. Fit of relational activity indicators", Scientometrics, Vol. 63, pp. 259-276. 
Bailon-Moreno, R., Jurado-Alameda, E. and Ruz-Banos, R. (2006), "The scientific network of surfactants: structural Analysis", Journal of the American Society for Information Science and Technology, Vol. 57, pp. 949-960.

Börner, K., Chen, C. and Boyack, K. (2003), "Visualizing knowledge domains", Annual Review of Information Science and Technology, Vol. 37, pp. 179-255.

Bottani, E. (2010), "Profile and enablers of agile companies: an empirical investigation", International Journal of Production Economics, Vol. 125, pp. 251-261.

Buckley, P.J. and Casson, M.C. (1976), The Future of the Multinational Enterprise, Macmillan, London.

Strategic

agility: a

bibliometric

approach

Buhalis, D. and O'connor, P. (2005), "Information communication technology revolutionizing tourism", Tourism Recreation Research, Vol. 30, pp. 7-16.

Cahlik, T. (2000), “Comparison of the maps of science”, Scientometrics, Vol. 49, pp. 373-387.

Callon, M., Courtial, J.P. and Laville, F. (1991), "Co-word analysis as a tool for describing the network of interactions between basic and technological research-the case of polymer chemistry", Scientometrics, Vol. 22, pp. 155-205.

Cerruti, C., Mena, C., Skipworth, H. and Tavoletti, E. (2016), "Characterizing agile supply partnerships in the fashion industry", International Journal of Operations and Production Management, Vol. 36, pp. 923-947.

Chadegani, A., Salehi, H., Yunus, M., Farhadi, H., Fooladi, M., Farhadi, M. and Ebrahim, N. (2013), “A comparison between two main academic literature collections: web of science and Scopus databases", Asian Social Science, Vol. 9, pp. 18-26.

Checkland, P. and Holwell, S. (1997), Information, Systems and Information Systems: Making Sense of the Field, John Wiley \& Sons, Chichester.

Chen, P. and Redner, S. (2010), "Community structure of the physical review citation network", Journal of Infometrics, Vol. 4, pp. 278-290.

Chen, C., Ibekwe-Sanjuan, F. and Hou, J. (2010), "The structure and dynamics of cocitation clusters: a multiple-perspective cocitation analysis", Journal of the American Society for Information Science and Technology, Vol. 61, pp. 1386-1409.

Cheng, C., Zhong, H. and Cao, L. (2020), "Facilitating speed of internationalization: the roles of business intelligence and organizational agility", Journal of Business Research, Vol. 110, pp. 95-103.

Clauss, T., Kraus, S., Kallinger, F.L., Bican, P., Brem, A. and Kailer, N. (2020), "Organizational ambidexterity and competitive advantage: the role of strategic agility in the explorationexploitation paradox", Journal of Innovation and Knowledge, forthcoming.

Clauss, T., Abebe, M., Tangpong, C. and Hock, M. (2021), "Strategic agility, business model innovation, and firm performance: an empirical investigation", IEEE Transactions on Engineering Management, Vol. 68, pp. 767-784.

Cobo, M.J., Lopez-Herrera, A.G., Herrera-Viedma, E. and Herrera, F. (2011a), "An approach for detecting, quantifying and visualizing the evolution of a research field: a practical application to the fuzzy sets theory field", Journal of Infometrics, Vol. 5, pp. 146-166.

Cobo, M.J., Lopez-Herrera, A.G., Herrera-Viedma, E. and Herrera, F. (2011b), "Science mapping software tools: review, analysis and cooperative study among tools", Journal of American Society for Information Science and Technology, Vol. 62, pp. 1382-1402.

Cobo, M.J., Lopez-Herrera, A.G., Herrera-Viedma, E. and Herrera, F. (2012), "SciMAT: a new science mapping analysis software tool", Journal of the American Society for Information Science and Technology, Vol. 63, pp. 1609-1630.

Cobo, M.J., Chiclana, F., Collop, A., de Ona, J. and Herrera-Viedma, E. (2014), "A bibliometric analysis of the intelligent transport systems research based on science mapping", IEEE Transactions on Intelligent Transportation Systems, Vol. 15, pp. 901-908. 
EJMBE 31,2

\section{4}

Cohen, D., Lindvall, M. and Costa, P. (2004), "An introduction to agile methods", Advances in Computers, Vol. 62, pp. 1-66.

Coulter, N., Monarch, I. and Konda, S. (1998), "Software engineering as seen through its research literature: a study in co-word analysis", Journal of the American Society for Information Science, Vol. 49, pp. 1206-1223.

Courtial, J.P. (1990), "A mathematical model of development in a research field", Scientometrics, Vol. 19, pp. 127-141.

Courtial, J.P. and Michelet, B. (1994), "A coword analysis of scientometrics”, Scientometrics, Vol. 31, pp. 251-260.

Da Silva, I.F., Da Mota Silveira Neto, P.A., O’leary, P., De Almeida, E.S. and De Lemos Meira, S.R. (2011), "Agile software product lines: a systematic mapping study", Software: Practice and Experience, Vol. 41, pp. 899-920.

Dabic, M., Vlacic, B., Paul, J. and Dana, L.-P. (2020), "Immigrant entrepreneurship: a review and research agenda", Journal of Business Research, Vol. 113, pp. 25-38.

De Jesus Marques, G. and Guerra, C.G. (2019), "Local Development Platforms (LDP): an operational framework for business development", European Journal of Management and Business Economics, Vol. 29, pp. 97-109.

Denning, S. (2018), The Age of Agile: How Smart Companies are Transforming the Way Work Gets Done, Amacom, New York.

Doz, Y.L. and Brannen, M.Y. (2012), "Corporate languages and strategic agility: trapped in your jargon or lost in translation?”, California Management Review, Vol. 54, pp. 77-97.

Doz, Y.L. and Kosonen, M. (2008), "The dynamics of strategic agility: nokia's rollercoaster experience”, California Management Review, Vol. 50, pp. 95-118.

Doz, Y.L. and Kosonen, M. (2010), "Embedding strategic agility: a leadership agenda for accelerating business model renewal", Long Range Planning, Vol. 43, pp. 370-382.

Ekman, A. and Angwin, D. (2007), "Industry patterns of agility: a study of the role of Information Systems and Information Technology as an antecedent of strategic agility within European organisations", International Journal of Agile Systems and Management, Vol. 2, pp. 360-375.

Elmoselhy, S.A.M. (2013), "Hybrid lean-agile manufacturing system technical facet, in automotive sector", Journal of Manufacturing Systems, Vol. 32, pp. 598-619.

Ezcan, V., Goulding, J.S. and Arif, M. (2020), "Redefining ICT embeddedness in the construction industry: maximizing technology diffusion capabilities to support agility", Building Research and Information, pp. 922-944.

Fernandez Alles, M. and Ramos Rodriguez, A.R. (2009), "Intellectual structure of human resources management research: a bibliometric analysis of the journal human resource management 1985-2005”, Journal of the American Society for Information Science and Technology, Vol. 60, pp. 161-175.

Fernando, Y. and Wulansari, P. (2020), "Perceived understanding of supply chain integration, communication and teamwork competency in the global manufacturing companies", European Journal of Management and Business Economics, Vol. 30, pp. 191-210.

Fink, L. and Neumann, S. (2007), "Gaining agility through IT personnel capabilities: the mediating role of IT infrastructure capabilities", Journal of the Association for Information Systems, Vol. 8, pp. 440-462.

Furrer, O., Thomas, H. and Goussevskaia, A. (2008), "The structure and evolution of the strategic management field: a content analysis of 26 years of strategic management research", International Journal of Management Reviews, Vol. 10, pp. 1-23.

Garcia Buendia, N., Moyano Fuentes, J., Maqueira Marin, J.M. and Cobo, M.J. (2020), "22 Years of Lean Supply Chain Management: a science mapping-based bibliometric analysis”, International Journal of Production Research, Vol. 59, pp. 1901-1921. 
Ghezzi, A. and Cavallo, A. (2020), "Agile business model innovation in digital entrepreneurship: lean startup approaches”, Journal of Business Research, Vol. 110, pp. 519-537.

Gligor, D.M., Esmark, C.L. and Holcomb, M.C. (2015), "Performance outcomes of supply chain agility: when should you be agile?", Journal of Operations Management, Vols 33-34, pp. 71-82.

Haider, S. and Mariotti, F. (2016), "Unfolding critical events and strategic decisions: the role of spatial and temporal cognition", Management Decision, Vol. 54, pp. 1813-1842.

Hamsal, S., Permadi, A., Musitama, T.N. and Bandur, A. (2020), "The impact of IT capability and supply chain agility in the electronic home appliance retail at Indonesia", International Journal of Advanced Trends in Computer Science and Engineering, Vol. 9, pp. 833-844.

Hartwell, C.A. and Devinney, T. (2021), "Populism, political risk, and pandemics: the challenges of political leadership for business in a post-COVID world", Journal of World Business, Vol. 56, pp. 1-17.

Harzing, A.W. and Alakangas, S. (2016), "Google scholar, Scopus and the web of science, a longitudinal and cross-disciplinary comparison”, Scientometrics, Vol. 106, pp. 787-804.

He, Q. (1999), "Knowledge discovery through co-word analysis”, Library Trends, Vol. 48, pp. 133-159.

Hendriyani, C. and Raharja, S.U.J. (2019), "Business agility strategy: peer-to-peer lending of Fintech startup in the era of digital finance in Indonesia", Review of Integrative Business and Economics Research, Vol. 8, pp. 239-246.

Hock, M., Clauss, T. and Schulz, E. (2016), “The impact of organizational culture on a firm's capability to innovate the business model", R\&D Management, Vol. 46, pp. 433-450.

Hsu, T.H. and Tang, J.W. (2020), "Development of hierarchical structure and analytical model of key factors for mobile app stickiness", Journal of Innovation and Knowledge, Vol. 5, pp. 68-79.

Ivory, S.B. and Brooks, S.B. (2018), "Managing corporate sustainability with a paradoxical lens", Journal of Business Ethics, Vol. 148, pp. 347-361.

Jacso, P. (2005), "As we may search-Comparison of major features of the web of science, scopus, and google scholar citation-based and citation-enhanced databases", Current Science, Vol. 89, pp. 1537-1547.

Jin, B., García, F. and Salomon, R. (2019), "Inward foreign direct investment and local firm innovation: the moderating role of technological capabilities", Journal of International Business Studies, Vol. 50, pp. 847-855.

Johnston, K. (2009), "Extending the marketing myopia concept to promote strategic agility", Journal of Strategic Marketing, Vol. 17, pp. 139-148.

Kamdem, J.P., Duarte, A.E., Rodrigues Lima, K.R., Teixeira, J.B., Rocha, W., Hassan, L., Mavirando Barros, L., Roeder, T. and Tsopmo, A. (2019), "Research trends in food chemistry: a bibliometric review of its 40 years aniversary (1976-2016)", Food Chenistry, Vol. 294, pp. 448-457.

Kappelman, L., Mclean, E., Johnson, V. and Gerhart, N. (2014), "The 2014 SIM IT key issues and trends study", MIS Quarterly, Vol. 13, pp. 237-263.

Kazakov, S., Ruiz-Alba, J.L. and Muñoz, M.M. (2020), "The impact of information and communication technology and internal market orientation blending on organisational performance in small and medium enterprises", European Journal of Management and Business Economics, Vol. 30, pp. 129-151.

Kohtamäki, M., Heimonen, J., Sjödin, D. and Heikkilä, V. (2020), "Strategic agility in innovation: unpacking the interaction between entrepreneurial orientation and absorptive capacity by using practice theory", Journal of Business Research, Vol. 118, pp. 12-25.

Kristianto, Y., Helo, P. and Takala, J. (2010), "Strategic inventory allocation for product platform strategy", Journal of Advances in Management Research, Vol. 7, pp. 233-249.

Lee, H. (1997), Temporal Implications of Electronically Mediated Business Procedures on Organisational Work: EDI Applications in Trade, London School of Economics and Political Science. 
EJMBE 31,2

\section{6}

Lewis, M., Andriopoulos, C. and Smith, W. (2014), "Paradoxical leadership to enable strategic agility", California Management Review, Vol. 56, pp. 58-77.

Lopez-Herrera, A.G., Cobo, M.J., Herrera-Viedma, E., Herrera, F., Bailon-Moreno, R. and JimenezConteras, E. (2009), "Visualization and evolution of the scientific structure of fuzzy sets research in Spain", Information Research, Vol. 14 No. 14, pp. 1-23.

Lopez-Herrera, A.G., Cobo, M.J., Herrera-Viedma, E. and Herrera, F. (2010), "A bibliometric study about the research based on hybridating the fuzzy logic field and the other computational intelligent techniques: a visual approach", International Journal of Hybrid Intelligent Systems, Vol. 17, pp. 17-32.

Luftman, J., Zadeh, H.S., Derksen, B., Santana, M., Rigoni, E.H. and Huang, Z.D. (2013), "Key information technology and management issues 2012-2013: an international", Journal of Information Technology, Vol. 28, pp. 354-366.

Luo, Y., Maksimov, V. and Bu, J. (2020), "Making geographic dispersion work for emerging market MNEs", Journal of International Management, pp. 1-19, forthcoming.

Malhotra, Y. (2005), "Integrating knowledge management technologies in organizational business processes: getting real time enterprises to deliver real business performance", Journal of Knowledge Management, Vol. 9, pp. 7-28.

Martin-Martin, A., Orduna-Malea, E., Thelwall, M. and Lopez-Cozar, E.D. (2018), "Google scholar, web of science and scopus: a systematic comparison of citations in 252 subject categories", Journal of Infometrics, Vol. 12, pp. 1160-1177.

Mathiassen, L. and Pries-Heje, J. (2006), "Business agility and difussion of information technology", European Journal of Information Systems, Vol. 15, pp. 116-119.

Mavengere, N. (2013), "Information technology role in supply chain's strategic agility", International Journal of Agile Systems and Management, Vol. 6, pp. 7-24.

Mongeon, P. and Paul-Hus, A. (2016), "The journal coverage of web of science and scopus: a comparative analysis", Scientometrics, Vol. 106, pp. 213-228.

Morris, S. and Van Der Veer Martens, S. (2008), "Mapping research specialties", Annual Review of Information Science and Technology, Vol. 42, pp. 213-295.

Naim, M.M. and Gosling, J. (2011), "On leanness, agility and leagile supply chains”, International Journal of Production Economics, Vol. 131, pp. 342-354.

Naylor, J.B., Naim, M.M. and Berry, D. (1999), "Leagility: integrating the lean and agile manufacturing paradigms in the total supply chain", International Journal of Production Economics, Vol. 62, pp. 107-118.

Nejatian, M., Zarei, M.H., Rajabzadeh, A., Azar, A. and Khadivar, A. (2019), "Paving the path toward strategic agility: a methodological perspective and an empirical investigation”, Journal of Enterprise Information Management, Vol. 32, pp. 538-562.

Nguyen, B.M., Tran, V. and Hluchy, L. (2012), "Developing and deploying cloud services based on abstraction approach", Journal of Digital Information Management, Vol. 10, pp. 254-261.

Noguera, I., Guerrero-Roldan, A.E. and Masa, R. (2018), “Computers and education”, Collaborative Agile Learning in Online Environments: Strategies for Improving Team Regulation and Project Management, Vol. 116, pp. 110-129.

Nyamrunda, F.C. and Freeman, S. (2021), "Strategic agility, dynamic relational capability and trust among SMEs in transitional economies", Journal of World Business, Vol. 56, pp. 1-26.

O'Reilly, C.A. III and Tushman, M.L. (2013), "Organizational ambidexterity: past, present, and future", Academy of Management Perspectives, Vol. 27, pp. 324-338.

Onn, C.W. and Sorooshian, S. (2013), "Mini literature analysis on information technology definition", Information and Knowledge Management, pp. 139-140. 
Pasamar, S., Diaz-Fernandez, M. and De La Rosa-Navarro, M.D. (2019), "Human capital: the link between leadership and organizational learning", European Journal of Management and Business Economics, Vol. 28, pp. 25-51.

Qi, Y., Boyer, K. and Zhao, X. (2009), "Supply chain strategy, product characteristics, and performance impact: evidence from Chinese manufacturers”, Decision Sciences, Vol. 40, pp. 667-695.

Raisch, S., Birkinshaw, J., Probst, G. and Tushman, M.L. (2009), "Organizational ambidexterity: balancing explotation and exploration for sustained performance", Organization Science, Vol. 20, pp. 685-695.

Ramos Rodriguez, A.R. and Ruiz Navarro, J. (2004), "Chagnes in the intellectual structure of strategic management research: a bibliometric study of the strategic management journal", Strategic Management Journal, Vol. 25, pp. 981-1004.

Rodriguez Ruiz, F., Almodovar, P. and Nguyen, Q.T.K. (2019), "Intellectual structure of international new venture research: a bibliometric analysis and suggestions for a future research agenda", Mutinational Business Review, Vol. 27, pp. 285-316.

Rogers, G., Szomszor, M. and Adams, J. (2020), "Sample size in bibliometric analysis", Scientometrics, Vol. 125, pp. 777-794.

Ross, J.W. and Westerman, G. (2004), "Preparing for utility computing: the role of IT architecture and relationship management", IBM Systems Journal, Vol. 43, pp. 5-19.

Rugman, A.M. (1981), Inside the Multinationals: the Economics of Internal Markets, Columbia University Press, New York.

Salomon, R.M. and Shaver, J.M. (2005), "Learning by exporting: new insights from examining firm innovation", Journal of Economics and Management Strategy, Vol. 14, pp. 431-460.

Sambamurthy, V., Bharadwaj, A. and Grover, V. (2003), "Shaping agility through digital options: reconceptualizing the role of information technology in contemporary firms", MIS Quarterly, Vol. 27, pp. 237-263.

Santiago, J. (2019), "The relationship between brand attractiveness and the intent to apply for a job", European Journal of Management and Business Economics, Vol. 28, pp. 142-157.

Schilke, O., Hu, S. and Helfat, C.E. (2018), "Quo vadis, dynamic capabilities? A content-analytic review of the current state of knowledge and recommendations for future research", Academy of Management Annals, Vol. 12, pp. 390-439.

Shaikh, I. (2021), "On the relation between the crude oil market and pandemic Covid-19", European Journal of Management and Business Economics, pp. 1-21, forthcoming.

Shams, R., Vrontis, D., Belyaeva, Z., Ferraris, A. and Czinkota, M.R. (2021), "Strategic agility in international business: a conceptual framework for 'agile' multinationals", Journal of International Management, Vol. 27, p. 100737.

Sharma, M. and Sehrawat, R. (2020), "Quantifying SWOT analysis for cloud adoption using FahpDematel approach: evidence from the manufacturing sector", Journal of Enterprise Information Management, Vol. 33, pp. 1111-1152.

Shuen, A., Feiler, P.F. and Teece, D.J. (2014), "Dynamic capabilities in the upstream oil and gas sector: managing next generation competition”, Energy Strategy Reviews, Vol. 3, pp. 5-13.

Simoes, E.D., Duarte, A.P., Neves, J. and Silva, V.H. (2019), "Contextual determinants of HR professionals' self perceptions of unethical HRM practices", European Journal of Management and Business Economics, Vol. 28, pp. 90-108.

Singh, V.K., Singh, P., Karmakar, M., Leta, J. and Mayr, P. (2021), "The journal coverage of Web of Science, Scopus and Dimensions: a comparative analysis", Scientometrics, Vol. 126, pp. 5113-5142.

Suradi, Mahrinasari, M.S. and Hasnawati, S. (2020), "The mediating effect of strategic agility in the relationship of supply chain management activities and firm performance of the textile industry of Indonesia”, International Journal of Supply Chain Management, Vol. 9, pp. 649-656.

Strategic agility: a bibliometric approach 
EJMBE 31,2

\section{8}

Teece, D. (2017), "Business models and dynamic capabilities”, Long Range Planning, Vol. 51, pp. 40-49.

Terjesen, S., Hessels, J. and Li, D. (2016), "Comparative international entrepreneurship: a review and research agenda", Journal of Management, Vol. 42, pp. 299-344.

Turner, P. (2014), "Removing the complexity in an interconnected world", Computer Fraud and Security, Vol. 2014, pp. 8-11.

Van Oosterhout, M., Waarts, E. and Van Hillegersberg, J. (2006), "Change factors requiring agility and implications for IT”, European Journal of Information Systems, Vol. 15, pp. 132-145.

Vargas, N., Lloria, M.B., Salazar, A. and Vergara, L. (2021), "Innovative outcome through exploration and exploitation - enablers, barriers and industrial property", European Journal of Management and Business Economics, pp. 1-17, forthcoming.

Vazquez-Bustelo, D., Avella, L. and Fernandez, E. (2007), "Agility drivers, enablers and outcomes. Empirical test of an integrated agile manufacturing model", International Journal of Operations and Production Management, Vol. 27, pp. 1303-1332.

Vieira, E. and Gomes, J. (2009), “A comparison of Scopus and Web of Science for a typical university”, Scientometrics, Vol. 81, pp. 587-600.

Vinodh, S. and Aravindraj, S. (2013), "Evaluation of leagility in supply chains using fuzzy logic approach", International Journal of Production Research, Vol. 51, pp. 1186-1195.

Wang, F.K. and He, W. (2014), "Service strategies of small cloud service providers: a case study of a small cloud service provider and its clients in Taiwan", International Journal of Information Management, Vol. 34, pp. 406-415.

Weber, Y. and Tarba, S.Y. (2014), "Strategic agility: a state of the art introduction to the special section on strategic agility", California Management Review, Vol. 56, pp. 5-12.

Weill, P., Subramani, M. and Broadbent, M. (2002), "Building IT infrastructure for: strategic agility", MIT Sloan Management Review, Vol. 44, pp. 57-65.

Worthington, J. (2004), "Repairing the business-IT relationship”, Cutter IT Journal, Vol. 17, pp. 5-10.

Xue, J., Shen, G.Q., Yang, R.J., Wu, H., Li, X., Lin, X. and Xue, F. (2020), "Mapping the knowledge dmain of stakeholder perspective studies in construction projects: a bibliometric approach", International Journal of Project Mangement, Vol. 38, pp. 313-326.

Zahra, S.A. (2021), "International entrepreneurship in the post Covid world", Journal of World Business, Vol. 56, pp. 1-7.

Zhu, Y. (2009), "Exploratory study on value of information systems to electrical construction companies: resource-based view”, Journal of Management in Engineering, Vol. 25, pp. 50-58.

Zhu, J. and Liu, W. (2020), "A tale of two databases: the use of web of science and Scopus in academic papers”, Scientometrics, Vol. 123, pp. 321-335.

\section{Corresponding author}

Enrique de Diego can be contacted at: endedieg@ucm.es

For instructions on how to order reprints of this article, please visit our website:

www.emeraldgrouppublishing.com/licensing/reprints.htm

Or contact us for further details: permissions@emeraldinsight.com 